\title{
S100B levels are affected by older age but not by alcohol intoxication following mild traumatic brain injury
}

\author{
Olga Calcagnile', Anders Holmén ${ }^{2}$, Michelle $\mathrm{Chew}^{3}$ and Johan Undén ${ }^{4 *}$
}

\begin{abstract}
Introduction: Biomarkers of brain damage and head injury are potentially useful tools in the management of afflicted patients. Particularly S100B has received much attention and has been adapted into clinical guidelines. Alcohol intoxication and higher age (65 years and over) have been used as risk factors for serious complications following head injury. The effect of these factors on S100B levels has not been fully established in a relevant patient cohort.

Methods: We prospectively included 621 adult patients with mild traumatic brain injury (TBI) and S100B sampling. Mild TBI was defined as Glasgow Come Scale 14-15 with loss of consciousness and/or amnesia, but without high-risk factors for intracranial complications. These patients would normally require CT scanning according to local and most international guidelines. S100B was sampled within 3 hours following trauma.

Results: 280 patients (45\%) were intoxicated by alcohol. Alcohol intoxication had no effect on S100B levels ( $p=0.65)$ and the performance of S100B remained unchanged in these patients. 115 patients (22\%) were 65 years or older with elevated S100B levels being more common in this group compared to patients under $65(p=0.029)$. Although the sensitivity of S100B was unchanged in older patients, the specificity was poorer.
\end{abstract}

Conclusion: S100B can be used reliably in mild TBI patients with alcohol intoxication. The clinically utility of S100B in older patients may be limited by very poor specificity leading to only a small decrease in CT scanning.

\section{Introduction}

Biochemical markers are used as screening and diagnostic tools in many clinical scenarios. Recently, biomarkers for diagnosis and prognosis of brain injury have developed [1]. These may allow faster and more accurate management of brain disease, similarly to biomarkers used in other organ systems. Traumatic brain injury (TBI) is a leading cause of death, especially in younger individuals [2]. Management usually involves computed tomography of the brain to detect lesions that may need neurosurgical or medical intervention. However, most of there injuries are not serious in nature, often called mild TBI or minor head injury. Serious complications following mild TBI are rare, with approximately $5 \%$ displaying traumatic $\mathrm{CT}$ pathology and less than $1 \%$ needing specific

\footnotetext{
* Correspondence: dr.johan.unden@gmail.com

${ }^{4}$ Department of Intensive Care and Perioperative Medicine and Institute of Clinical Sciences Malmö, Lund University, Skanes University Hospital, Malmo 20502, Sweden

Full list of author information is available at the end of the article
}

intervention $[3,4]$. Despite this, CT is recommended in these patients due to the seriousness of the complications [5-7]. Attempts to reduce CT use have been based upon aspects of patient history and clinical examination. However, these may be inaccurate in any patients, especially in those with head trauma or brain injury. An objective biomarker would therefore we welcomed in the management of these patients.

S100B is a small calcium-binding protein weighing approximately $21 \mathrm{kDa}$, predominantly expressed by glia cells. When brain tissues and/or the blood brain barrier (BBB) are damaged, S100B is released and can be detected in the peripheral blood. Many studies have shown the potential of $\mathrm{S} 100 \mathrm{~B}$ as a biomarker in brain injuries [8-10]. In particular, the potential of S100B to reduce unnecessary $\mathrm{CT}$ scans following mild TBI has received considerable attention. Recently, international guidelines have been published including $\mathrm{S} 100 \mathrm{~B}$ as a management option [11].

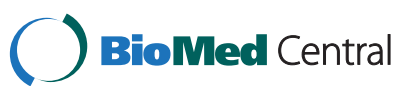


Many patients with mild TBI are intoxicated by ethanol [12]. Although some studies have shown little effect of alcohol on S100B levels [12], others have shown conflicting results [13]. This aspect is important if the biomarker is to function effectively in this population. False high S100B due to alcohol intoxication would limit the CT-reducing ability of the biomarker.

Children have higher levels of S100B than adults [14]. However, levels of S100B in elderly patients following mild TBI have not been investigated. Since older age (most often defined as over 65 years of age) is often included as a risk factor for complications after TBI $[15,16]$, this aspect is also of importance.

The aim of this study is to investigate the relationship of older age and alcohol intoxication to serum S100B levels following mild TBI in a large prospective cohort.

\section{Methods}

\section{Study setting and cohort population}

We undertook a prospective study in Halmstad Regional hospital, Sweden, from June 2008 to December 2012. Our hospital is a level II trauma centre with 24-hour emergency care, anesthesiology, radiology, surgery and intensive care. Approximately 6 months prior to the study, local guidelines for management of mild TBI, including S100B sampling, were introduced into clinical practice.

We consecutively enrolled all adult patients with mild TBI and subsequent S100B sampling. Inclusion criteria were; adult patients with trauma to the head with GCS 14-15 during examination and loss of consciousness < 5 minutes or amnesia. Exclusion criteria were; age less than 18 years, focal neurological deficit, therapeutic anticoagulation or haemophilia, radiographically demonstrated skull fracture, clinical signs of depressed skull fracture or skull base fracture, posttraumatic seizure, shunt-treated hydrocephalus, multiple organ trauma and patients where serum sampling for S100B was taken more than 3 hours post-injury.

Patient age at time of trauma and alcohol intoxication (yes/no based upon patient history and examination) was prospectively documented. Determination of blood alcohol levels was determined based upon the discretion of the treating physician. The age limit of 65 years or older was the pre-determined cut-off for analysis based upon published management rules [11,16].

The study was approved by the regional ethical board (approval number 19/2007).

\section{Blood sampling and biochemical analysis}

A $5 \mathrm{ml}$ blood sample was drawn from patient's cubital vein in the ED. Samples were analyzed with the fully automated Elecsys ${ }^{\circ}$ S100 (Roche AB) at the Clinical Chemistry Department of Halmstad Regional hospital, Sweden. Roche $\mathrm{AB}$ report a range between $0.005 \mu \mathrm{g} / \mathrm{L}$ and $39 \mu \mathrm{g} / \mathrm{L}$ and a within-series coefficient of variance of $<2.1 \%$. Based on the available evidence at this time, we chose a cut-off level for normal levels of less than $0.10 \mu \mathrm{g} / \mathrm{L}$ and a window of sampling of 3 hours from the time of the accident $[17,18]$. Lab results were available to treating physicians within 1 hour after sampling.

\section{CT examinations}

Cranial CT scans were performed with a GE VCT Ligthspeed 64 multislice detector with a 0,625/0,625 mm, 0,5 seconds rotation time and pitch of 0,531:1. $10 \mathrm{~mm}$ thick slices were used as part of the standard CT protocol for these patients. CT scans are always analysed by a board certified radiologist and confirmed by a consultant radiologist. Since S100B was used clinically, radiologists were not blinded to S100B results. A CT scan was considered positive if any sings of cranial (skull fracture) or intracranial pathology (hematoma, air or contusion) were present.

\section{Follow-up}

Patients were followed up after 3 months post-trauma by questionnaire. This contained information regarding clinical symptoms suggestive of intracranial complications and included additional (new) CT scans and/or exposure to the health care system. Patients who were lost to follow-up were checked by examination of medical records and national mortality databases for signs of intracranial complications or death.

\section{Statistic analysis}

Data was registered on an Excel ${ }^{\circ}$ file. The difference in S100B levels between age groups and intoxicated/sober patients were calculated with a Mann-Whitney test. A non-parametric test was chosen due to a skewed distribution of data.

\section{Results}

Between June 2008 and December 2012, we enrolled 621 patients with mild TBI and S100B levels. 351 patients had CT scans as part of their management (322 with S100B levels equal to or higher than $0.10 \mu \mathrm{g} / \mathrm{L}$ and 29 patients with S100 levels lower than $0.10 \mu \mathrm{g} / \mathrm{L}$ ). 513 (83\%) of patients had successful and complete follow-up including 242 (90\%) of the 270 patients not receiving an initial CT. No patients showed any new signs of intracranial complications. A total of 29 patients had cranial CT pathology but only 26 (4.7\%) of these showed traumatic abnormalities (isolated skull fracture $\mathrm{n}=3$, cerebral contusions $\mathrm{n}=9$, acute subdural hematoma $\mathrm{n}=3$, intracranial air $n=1$, combinations of traumatic intracranial findings $\mathrm{n}=10$ ). The remaining 3 patients had non-traumatic findings unrelated to the injury.

280 patients $(45 \%)$ were intoxicated by alcohol and a blood alcohol level was determined in 197 patients. All 


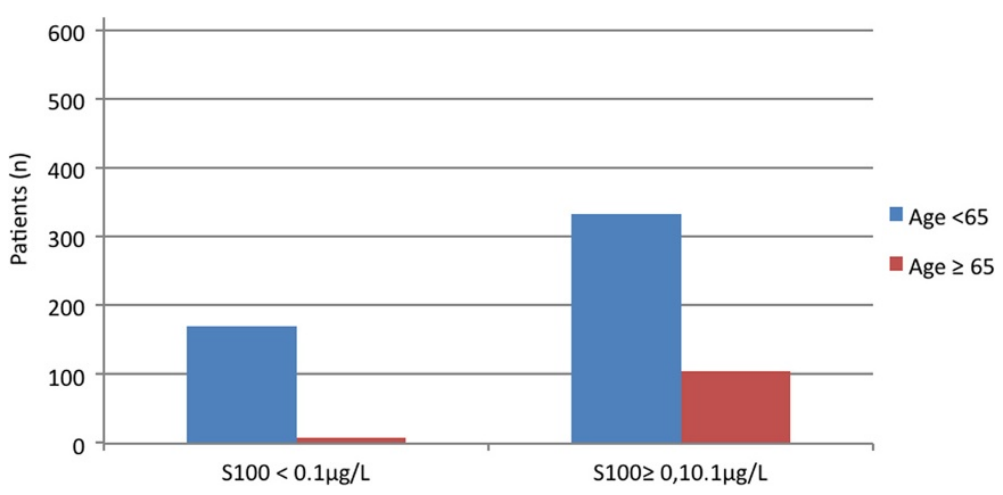

Figure 1 Bar graph showing the relationship between age and S100B levels.

patients who had blood drawn for alcohol analysis were clinically suspected of intoxication and all had measureable levels. 115 patients (19\%) of the total cohort were 65 years or older.

180 patients (29\%) had a S100B level lower than $0.10 \mu \mathrm{g} / \mathrm{L}: 171$ of these $(95 \%)$ were younger than 65 years and only 9 patients (5\%) were older or equal than 65 years of age. Figure 1 shows a bar graph of age and S100B levels in the study population. 441 patients (71\%) showed a S100B level higher or equal to $0.10 \mu \mathrm{g} / \mathrm{L}: 335$ (76\%) of these were younger than 65 years old and 106 patients $(24 \%)$ were older or equal than 65 years old. The difference in S100B levels between the age groups was significant $(\mathrm{p}=0.029)$, see Table 1 . A scatter plot of age verses S100B levels is shown in Figure 2.

Table shows the number of patients (and interquartile range in brackets) with S100B levels above and below $0.10 \mu \mathrm{g} / \mathrm{L}$ and the number of patients above or below 65 years of age and with or without alcohol intoxication. The difference in S100B levels between patients 65 and over with patients under 65 years was significant $(p=0.029)$ and the difference between intoxication and no intoxication was not significant $(\mathrm{p}=0.65)$.

206 of the 280 patients (74\%) who were intoxicated by alcohol had a S100B level higher or equal to $0.10 \mu \mathrm{g} / \mathrm{L}$.
235 of the 338 (70\%) patients without alcohol intoxication had elevated S100B levels. There was no statistical difference in S100B levels between those patients with and without intoxication $(\mathrm{p}=0.65)$, see Table 1 . For the 197 patients where serum ethanol levels were determined, a scatterplot was created, see Figure 3. 10 patients were both 65 years or older and intoxicated by alcohol.

S100B had a sensitivity of $100 \%$ and a specificity of $30 \%$ for CT findings in the entire population. The specificity increased to $35 \%$ if only patients younger than 65 years were considered. The positive likelihood ratio that a S100B level higher or equal to $0.10 \mu \mathrm{g} / \mathrm{L}$ would predict a pathological CT was 1.44 for the entire population while it increased to 1.54 if we considered only patients younger than 65 years of age.

\section{Discussion}

The initial management of mild TBI is still under debate. Several guidelines and decision rules, derived from different cohorts from different countries, have been published and are currently used clinically $[11,15,16,19]$. The introduction of S100B into clinical practice has been shown to improve the management of mild TBI [20] with a reduction of CT scans following these injuries. This has the potential to reduce costs

Table 1 S100B levels in 621 patients with mild TBI

\begin{tabular}{|c|c|c|c|c|}
\hline & $\mathrm{S} 100 \mathrm{~b}<0.10 \mu \mathrm{g} / \mathrm{L}$ & $\begin{array}{c}\text { Median S100b } \\
\mu \mathrm{g} / \mathrm{L}\end{array}$ & $\mathrm{S} 100 \mathrm{~b} \geq 0.10 \mu \mathrm{g} / \mathrm{L}$ & $\begin{array}{c}\text { Median S100b } \\
\mu \mathrm{g} / \mathrm{L}\end{array}$ \\
\hline \multirow[t]{2}{*}{$<65$ years } & 171 patients & 0.07 & 335 patients & 0.19 \\
\hline & & $(0.03-0.09)$ & & $(0.10-4.51)$ \\
\hline \multirow[t]{2}{*}{$\geq 65$ years } & 9 patients & 0.07 & 106 patients & 0.23 \\
\hline & & $(0.04-0.09)$ & & $(0.10-6.75)$ \\
\hline \multirow[t]{2}{*}{ No Alcohol intoxication } & 106 patients & 0.07 & 235 patients & 0.20 \\
\hline & & $(0.03-0.09)$ & & $(0.10-6.75)$ \\
\hline \multirow[t]{2}{*}{ Alcohol intoxication } & 74 patients & 0.07 & 206 patients & 0.20 \\
\hline & & $(0.03-0.09)$ & & $(0.10-4.51)$ \\
\hline
\end{tabular}




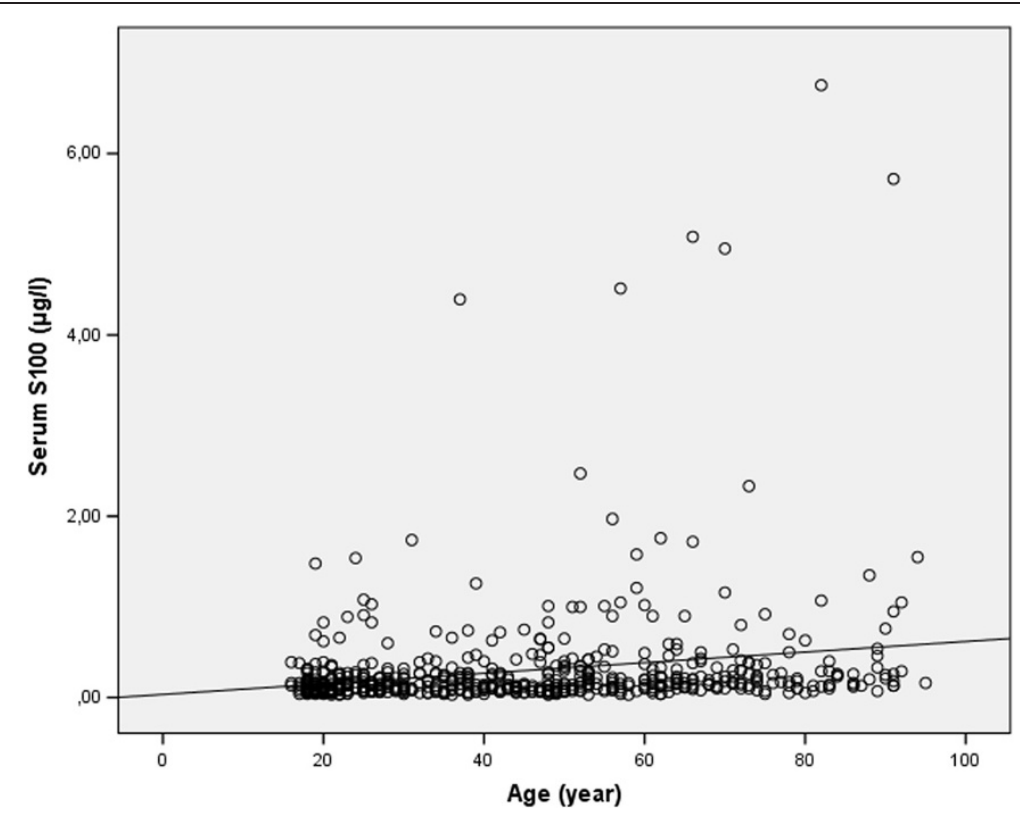

Figure 2 Scatter plot showing S100B levels verses age in patients following mild TBI. Spearman's rho 0,295, $p=0,000$.

and potential radiation dosages to patients with head injury.

New, updated international guidelines, including blood sampling for S100B, are presently being implemented in Scandinavia [11]. These guidelines recommend S100B sampling in adult patients with loss of consciousness and/or repeated (more than one episode) vomiting if other risk factors are absent. One such risk factor is older age (65 years or older) in combination with anti-thrombocyte medication. As many elderly patients take these medications, the majority of these patients will have this risk factor and not be eligible for S100B sampling. Based upon the results of this study, this approach seems reasonable. Even if the sensitivity of S100B for CT findings was still 100\% in elderly patients, the specificity was worse. In practice, this results in a smaller potential reduction in CT scanning after mild

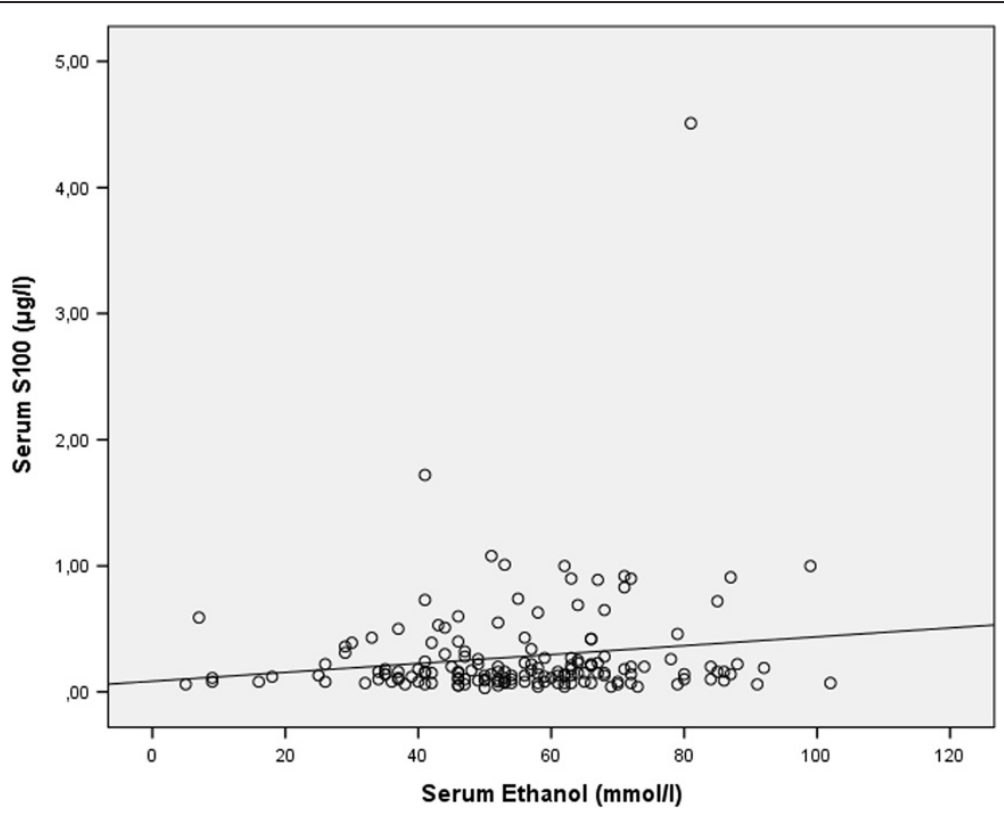

Figure 3 Scatter plot showing S100B levels verses serum ethanol levels in patients following mild TBI. Spearman's rho 0,092, $p=0,249$. 
TBI and hence a weaker clinical indication for the test. The reason for this observation is unclear. One may speculate that the higher S100B levels observed are merely a reflection of the increased risk of brain injury these patients have following brain trauma. If this is the case, S100B levels may still correctly classify these patients as high risk mild TBI indicating the necessity of a CT scan. Also, older patients often have concurrent chronic disease and may also have neurological disease such as Alzheimer's disease or Parkinson's disease. In the present study, non-neurological disease was not registered and the prevalence of neurodegenerative disease was too low to perform any meaningful analysis. It may also be argued that the cut-off for S100B should be higher in older patients. This was, however, not an endpoint of this study. Higher cut-off levels have been shown to be more specific in previous studies [21]. However, the large body of evidence and current clinical practice is focused on the $0.10 \mu \mathrm{g} / \mathrm{L}$ level and is seems reasonable to primarily consider this cut-off although to ensure maximal sensitivity in clinical practice. These issues should be confirmed in future studies.

We found no affect of alcohol on S100B levels, irrespective of whether alcohol intoxication was derived from patient history and clinical examination or from objective blood ethanol levels. This confirms previous observations from another cohort [12] but is somewhat in contrast to other reports [13]. Different methods of S100B analysis may have influenced these conflicting results [22]. The results from this study are based upon a much larger cohort than the previous studies and consider a pragmatic and clinically relevant patient material. This observation is important considering the frequency of alcohol intoxication in these patients. Indeed, in this study, $45 \%$ of patients were intoxicated by alcohol.

Considering these results, S100B can be used freely in mild TBI patients with alcohol intoxication. This is naturally welcomed, due to the difficulties of assessing patient history, performing adequate and reliable clinical examination and obtaining a cranial CT scan of intoxicated patients. Although S100B shows a 100\% sensitivity for CT findings after mild TBI in all age groups, the performance of the biomarker, specifically the ability of S100B to decrease unnecessary CT scans, will likely be reduced in elderly (65 years or older) patients. Although this is in accordance to recent guidelines [11], this should also be considered in other scenarios. The health economic implications of S100B use in this patient group remains to be shown.

\section{Conclusion}

In patients with mild TBI, S100B is unaffected by alcohol intoxication and may be used effectively in this patient group. Patients aged 65 years and older had higher S100B levels and the overall ability of S100B to reduce CT scans in the elderly may be impaired.

\section{Competing interests}

$J U$ has in previous studies (unconnected with the current study) received S100B analysis kits from Roche AB, Sweden and Diasorin AB, Sweden. JU has previously lectured for Roche $A B$, Sweden. $A H, O C$ and $M C$ did not have any competing interests.

\section{Authors' contributions}

$J U$ and $O C$ conceived the study. $J$ and $O C$ acquired data. $J, A H, M C$ and $J U$ did data analysis. $J U$ and $\mathrm{OC}$ drafted the paper with input from $\mathrm{AH}$ and MC. All authors read and approved the final manuscript.

\section{Author details}

'Department of Pediatric Medicine, Hallands Hospital, Halmstad 30185, Sweden. 'Department of Research and Development, Hallands Hospital, Halmstad 30185, Sweden. ${ }^{3}$ Department of Anaesthesia and Intensive Care and Institute of Clinical Sciences Malmö, Lund University, Hallands Hospital, Halmstad 30185, Sweden. ${ }^{4}$ Department of Intensive Care and Perioperative Medicine and Institute of Clinical Sciences Malmö, Lund University, Skanes University Hospital, Malmo 20502, Sweden.

Received: 15 May 2013 Accepted: 3 July 2013

Published: 6 July 2013

\section{References}

1. Ingebrigtsen $T$, Romner B, Kongstad $P$, Langbakk B: Increased serum concentrations of protein S-100 after minor head injury: a biochemical serum marker with prognostic value? J Neurol Neurosurg Psychiatry 1995, 59(1):103-104

2. Soreide $K$, Kruger AJ, Vardal AL, Ellingsen CL, Soreide E, Lossius HM: Epidemiology and contemporary patterns of trauma deaths: changing place, similar pace, older face. World J Surg 2007, 31(11):2092-2103.

3. Morton MJ, Korley FK: Head computed tomography use in the emergency department for mild traumatic brain injury: integrating evidence into practice for the resident physician. Ann Emerg Med 2012, 60(3):361-367.

4. Af Geijerstam JL, Britton M: Mild head injury - mortality and complication rate: meta-analysis of findings in a systematic literature review. Acta Neurochir (Wien) 2003, 145(10):843-850. discussion 850.

5. Stein SC: Indications for computed tomography after minor head injury. N Engl J Med 2000, 343(21):1570. author reply 1571.

6. Stein SC: Mild head injury. J Neurosurg 2005, 102(1):183-184. author reply 185 .

7. Ingebrigtsen T, Romner B, Kock-Jensen C: Scandinavian guidelines for initial management of minimal, mild, and moderate head injuries. The Scandinavian Neurotrauma Committee. J Trauma 2000, 48(4):760-766.

8. Pelinka LE, Kroepfl A, Leixnering M, Buchinger W, Raabe A, Redl H: GFAP versus $\mathrm{S} 100 \mathrm{~B}$ in serum after traumatic brain injury: relationship to brain damage and outcome. J Neurotrauma 2004, 21(11):1553-1561.

9. Foerch C, Wunderlich MT, Dvorak F, Humpich M, Kahles T, Goertler M, Alvarez-Sabin J, Wallesch CW, Molina CA, Steinmetz H, et al: Elevated serum S100B levels indicate a higher risk of hemorrhagic transformation after thrombolytic therapy in acute stroke. Stroke 2007, 38(9):2491-2495.

10. Mussack T, Biberthaler P, Wiedemann E, Kanz KG, Englert A, Gippner-Steppert C, Jochum M: S-100b as a screening marker of the severity of minor head trauma (MHT)-a pilot study. Acta Neurochir Suppl 2000, 76:393-396.

11. Unden J, Ingebrigtsen T, Romner B: Scandinavian guidelines for initial management of minimal, mild and moderate head injuries in adults: an evidence and consensus-based update. BMC Med 2013, 11:50.

12. Mussack T, Biberthaler P, Kanz KG, Heckl U, Gruber R, Linsenmaier U, Mutschler W, Jochum M: Immediate S-100B and neuron-specific enolase plasma measurements for rapid evaluation of primary brain damage in alcohol-intoxicated, minor head-injured patients. Shock 2002, 18(5):395-400.

13. Lange RT, Iverson GL, Brubacher JR: Clinical utility of the protein S100B to evaluate traumatic brain injury in the presence of acute alcohol intoxication. J Head Trauma Rehabil 2012, 27(2):123-134.

14. Astrand R, Romner B, Lanke J, Unden J: Reference values for venous and capillary S100B in children. Clin Chim Acta 2011, 412(23-24):2190-2193. 
15. Haydel MJ, Preston CA, Mills TJ, Luber S, Blaudeau E, DeBlieux PM: Indications for computed tomography in patients with minor head injury. N Engl J Med 2000, 343(2):100-105.

16. Stiell IG, Wells GA, Vandemheen $\mathrm{K}$, Clement $\mathrm{C}$, Lesiuk $\mathrm{H}$, Laupacis $\mathrm{A}$, McKnight RD, Verbeek R, Brison R, Cass D, et al: The Canadian CT head rule for patients with minor head injury. Lancet 2001, 357(9266):1391-1396.

17. Biberthaler P, Linsenmeier U, Pfeifer K, Kroetz M, Mussack T, Kanz KG, Hoecherl EF, Jonas F, Marzi I, Leucht P, et al: Serum S-100B concentration provides additional information fot the indication of computed tomography in patients after minor head injury: a prospective multicenter study. Shock 2006, 25(5):446-453.

18. Muller K, Townend W, Biasca N, Unden J, Waterloo K, Romner B, Ingebrigtsen T: S100B serum level predicts computed tomography findings after minor head injury. J Trauma 2007, 62(6):1452-1456.

19. Smits M, Dippel DW, Steyerberg EW, de Haan GG, Dekker HM, Vos PE, Kool DR, Nederkoorn PJ, Hofman PA, Twijnstra A, et al: Predicting intracranial traumatic findings on computed tomography in patients with minor head injury: the CHIP prediction rule. Ann Intern Med 2007, 146(6):397-405.

20. Calcagnile O, Unden L, Unden J: Clinical validation of S100B use in management of mild head injury. BMC Emerg Med 2012, 12:13.

21. Cervellin G, Benatti M, Carbucicchio A, Mattei L, Cerasti D, Aloe R, Lippi G: Serum levels of protein $\mathrm{S} 100 \mathrm{~B}$ predict intracranial lesions in mild head injury. Clin Biochem 2012, 45(6):408-411.

22. Muller K, Elverland A, Romner B, Waterloo K, Langbakk B, Unden J, Ingebrigtsen T: Analysis of protein S-100B in serum: a methodological study. Clin Chem Lab Med 2006, 44(9):1111-1114.

doi:10.1186/1757-7241-21-52

Cite this article as: Calcagnile et al: S100B levels are affected by older age but not by alcohol intoxication following mild traumatic brain injury. Scandinavian Journal of Trauma, Resuscitation and Emergency Medicine 2013 21:52

\section{Submit your next manuscript to BioMed Central and take full advantage of:}

- Convenient online submission

- Thorough peer review

- No space constraints or color figure charges

- Immediate publication on acceptance

- Inclusion in PubMed, CAS, Scopus and Google Scholar

- Research which is freely available for redistribution 